\title{
„Intermedijalna osjetljivost" poezije Antuna Gustava Matoša, perspektiva lirskog subjekta
}

\begin{abstract}
Jukić Sanja, „Intermedijalna osjetljivost” poezije Antuna Gustava Matoša, perspektiva lirskog subjekta (,Intermedial Sensitivity” of Antun Gustav Matoš’s Poetry, the Perspective of the Lyrical Subject). „Poznańskie Studia Slawistyczne” 7. Poznań 2014. Publishing House Science and Innovate, pp. 119-128. ISBN 978-83-63795-79-5. ISSN 2084-3011.

The paper aims to show that the lyrical subject of Matoš's poetry is indeed a media hybrid structure. This subject usually identifies with the signifiers of other artistic media, such as the theater, dance, music, painting, fashion and architecture. Therefor, Matoš's lyrical subject reveals itself as a media hybrid being, which is defined by both time and culture.
\end{abstract}

Keywords: intermedial sensitivity; poetic subject; cultural construction of the subject; symbolism; modernism; artism

\section{Uvod}

Rad nastoji pokazati kako se u Matoševu lirskom opusu pojavljuje lirski subjekt koji je medijski hibridna struktura $^{1}$ što se identificira strategijama

${ }^{1}$ Medijski je subjekt kao instanca hibridne konstitucije elaboriran u doktorskoj disertaciji autorice ovog rada, gdje se on određuje kao strukturna posljedica kulturalnih okolnosti, posebice dinamike različitih tehnologijskih međukontakata, što na različite načine $u$ tekst posreduje „medijsku kulturu” (medijska kultura tumači se kao „svakodnevna javna i privatna kultura determinirana prikazima, produktima i efektima masovne komunikacije omogućene visoko razvijenom komunikacijskom tehnologijom", Šuvaković 2005: 364) kojoj pripada. Medijski je subjekt protočište drugokodnih signala i uspostavlja se kao kodno hibridna 
drugih umjetničkih medija. Treba napomenuti kako je sintagma „intermedijalna osjetljivost" primjenjiva kao terminološka oznaka i vremenske i poetološko-stilske informativnosti Matoševa pjesničkog opusa. Naime, u studiji o pjesništvu intermedijalnog iskustva Goran Rem ,pjesništvom intermedijalne osjetljivosti” označava ono pjesništvo čije strukture pokazuju postojanje intermedijalnih strategija prije teorijske elaboracije pojma intermedijalnost, a ,intermedijalnim pjesništvom” imenuje teorijski osviještenu produkciju, s tim što vremensku granicu tih dviju poetološko-stilskih paradigmi smješta u točku prijelaza 60-ih godina XX. stoljeća u 70-e (Rem 2011: 63-68).

U protointermedijalno pjesništvo Rem, među ostalim, uvrštava i pjesničke tekstove Antuna Gustava Matoša te kao paradigmatski primjer navodi pjesmu Epitaf bez trofeja u kojoj grafika oponaša tekst skulpture. Osim toga, Rem spominje i filmičnost jedne od najpoznatijih Matoševih pjesama Jesenje veče, i to posebice na razini stilizacije različitog stupnja, smjera i kretanja tekstualnih osvjetljenja (Rem 2011).

O vezama Matoševe poezije s glazbom kroz formalnu realizaciju glazbenosti pisali su, primjerice, Ivan Slamnig (1981) i Zoran Kravar (Kravar, Oraić Tolić 1996), a potonji je spomenuo i supstituciju arhitekture zvukovnim efektima u pjesmi Notturno ${ }^{2}$. O likovnoj dimenziji Matoševe poezije može se čitati kod Dubravke Oraić Tolić koja piše o „osjetilnoj vizualnosti” Matoševih pjesama (2003: 383-389) ${ }^{3}$. I sâm Antun Gustav Matoš u jednoj se od svojih likovnih kritika izravno dotaknuo veze poezije i likovnosti. Pišući o slici Smrt kneza Lazara srpskog slikara realista Đorđa Krstića (Matoš 1973: 24-26), uočio je kako je slika koju je analizirao kao svojevrsnu interpretaciju teksta iz narodne književnosti, inferiorna u odnosu na slikovne podatke koje donosi njezin pjesnički prototekst.

instanca - i u smislu funkcije posredovanja, i u smislu drugomedijske identitetnosti, zbog čega se i imenuje medijskim subjektom (Jukić 2011: 7-10).

${ }^{2}$ „U Notturnu prostor gubi arhitekturu i svodi se na medij međusobno prepletenih zvukovnih signala" (Kravar, Oraić Tolić 1996: 20).

3 Oraić Tolić razlikuje tri paradigme vizualnosti u hrvatskoj književnosti XX. stoljeća - osjetilnu (na prijelomu XIX. i XX. stoljeća, čime se referira na kulturu moderne u srednjoeuropskom smislu), epistemološku (referira prvu trećinu XX. stoljeća, odnosno kulturu avangarde te modernizam kao stil) i imaginarnu vizualnost (kraj XX. stoljeća, razdoblje postmoderne) (Oraić Tolić 2003: 382-383). 
Reference iz kojih se vidi kako se o intermedijalnim implikacijama Matoševe poezije znanstveno razmišljalo i pisalo, mogle bi se nizati i dalje, no priđe li se toj problematici iz perspektive instance subjekta, može se zapaziti i jedna manje razrađena dimenzija Matoševe protointermedijalne strategije - Matoš je sklon maskiranju lirskog subjekta različitim drugomedijskim označiteljima.

\section{Identifikacijske strategije}

Matoš, naime, često uz identifikaciju humanitetnog subjekta:

- geobiografskim označiteljima (u pjesmi Serenada: „Ja te volim, jer si ljubav Zemlje / Iz koje niknuh, Hrvatice draga" [istaknula S.J.; Matoš 1996: 12], pri čemu je velikoslovni početak leksema „Zemlja” signal njegove semantičke udvojenosti koji zahtijeva simboličko preoznačavanje na relaciji globalno-nacionalno),

- biološkim, tj. spolnim označiteljima (gramatičkim signalima, eksplicitnim označiteljima spola ,žena”, „djevojčica”, nominacijskim oznakama - u pjesmi Djevojčici umjesto igračke: „Ljerko, srce moje, ti si lutka mala” [Matoš 1996: 29 i slj.]),

- mitološkim likovima (Dijana, Luna, Venera, muze i sl, ili)

- poetološkim sugestijama romantičarskog simbolizma (u pjesmi Čuvi$d a$ : „S maskom simbol, Žena i Sirena, / Sjeća me na Poea [...i Montépina!]" [Matoš 1996: 9]),

provodi njegovu identifikaciju različitim označiteljima drugoumjetničkih medija (plesnog, slikarskog, kiparskog, arhitekturnog, glazbenog ili kazališnog), što ovaj rad primarno i zanima. Može se reći kako se takvim višestruko simbolički posredovanim pristupom odnosu zbilje i, u najvećoj mjeri, subjektne (humanitetne) strukture pjesničkog teksta, uspostavlja svojevrsna globalna teatralizacija lirske radnje, odnosno artificijelizacija zbilje nauštrb referencijalnosti.

\section{Tko je subjekt?}

Neknjiževnim se medijskim oznakama identificiraju i prvoosobni govorni subjekt i sugovorni drugoosobni, odnosno objektivirani trećeosobni 
subjekt. Kazališni je medij, primjerice, u korelaciji s medijima plesa i glazbe, sredstvo subjektove identifikacije u pjesmama Čuvida (tal. ciovetta maska, krinka, obrazina, maškara, krabulja, lažan izgled; Klaić 1979: 250) i Djevojčici umjesto igračke.

Zoran Kravar Čuvidu je označio „lirskom bufonerijom” te je uvrstio u poeziju lirskog humora zajedno s onim pjesmama Matoševa opusa što se referiraju na različite konkretne i opće aktualnosti njegova vremena. Uz $\check{C}$ uvidu stoji bilješka kako vjerojatno nema određene adrese, ali je privlačna duhovitim rimama i formulacijama (Kravar, Oraić Tolić 1996: 24-26). Međutim, mišljenja smo da je ,adresa” ipak utvrdiva, a onda i semantika cijele karnevalsko-glazbeno-plesne fantazmatske slike ovog teksta. Naime, od kraja XVIII. do u početak XX. stoljeća zagrebački je društveni život poznat po pokladnim balovima ${ }^{4}$ čija se organizacija kroz tih stotinjak godina može čitati kao svojevrsni društveno-povijesni vremeplov koji otkriva promjene u društvenoj hijerarhiji, procese demokratizacije i nacionalnog osvješćivanja kroz supstituciju inozemnih elemenata plesa i mode nacionalnima (cf. Katarinčić 2005). Ti su plesovi, u svojim početcima, i to oni u plemićkim krugovima, često imali i kazališne elemente humornog tipa s mitološkim likovima ${ }^{5}$ te glazbenu pratnju (u kasnijim razvojnim fazama tih plesova i u građanskim slojevima), a zabilježeni su i erotski segmenti. Kad su se pojavile, ,plesne zabave ubrzo postaju moda i mjesto gdje su vladajući zagrebački slojevi provodili svoj društveni život” (Katarinčić 2005: 51) i posve je sigurno da je Matoš bio upućen u njihov društveni utjecaj te da je u kreiranju svog teksta na njih kontekstno i aludirao (i ne samo u pjesmi Čuvida, već i u drugospomenutoj Djevojčici umjesto igračke, no s drukčijim konotacijama). Subjekt u pjesmi Čuvida tako je akter jednoga takvog

4 „Ples je dominirao u javnom društvenom životu Zagrepčana u pokladno vrijeme kad je bio najomiljeniji način provođenja slobodnog vremena i zabave. U skladu s raspoloženjem, plesovi su se često izvodili pod maskama. Osim u pokladno vrijeme u Zagrebu se plesalo prigodom većih gradskih svečanosti, tijekom važnijih događanja, nakon glazbenih koncerata, prigodom privatnih večernjih druženja i slično. (...) U Zagrebu su se, dakle, javne plesne zabave odvijale uglavnom i najviše o pokladama. Međutim, i tu je bilo iznimaka pa tako znamo da su se neke zabave u Zagrebu održavale u povodu iznimnih događanja, kojima se ponekad može pridodati značaj (političkih) rituala" (Katarinčić 2005: 56, 64-65).

5 ,Žive su slike nijemi i nepomični kazališni izvodi bez glazbene pratnje, predstavljani u palačama plemića, na pozornici i drugim javnim prostorima, uglavnom mitološke tematike" (Katarinčić prema Batušić 2005: 50). 
karnevalsko-kazališno-plesno-glazbenog bala, pri čemu se njegova identifikacija višestruko odgađa, zapravo se i ne događa, osim na razini višestrukog prerušavanja, tj. višestrukog izmjenjivanja uloga, odnosno maskirne identitetnosti (Kolombina $\rightarrow$ sablast $\rightarrow$ markiza $\rightarrow$ Venus $\rightarrow$ Žena $\rightarrow$ Sirena $\rightarrow$ mačka $\rightarrow$ zmija $\rightarrow$ smaragd). Upravo taj smjer prerušavanja - od tipske maskiranosti (Kolombina), koja tu maskiranost, paradoksalno, na neki način i poništava, prema maskirnoj umnoženosti, odnosno individualizaciji maske i potpunoj nemogućnosti subjektova identitetnog razaznavanja, protumačiv je kao simbolička izvedba promjene subjektne paradigme koje je Matoš i te kako bio svjestan - od predmodernističkoga javnog pojedinca „koji igra točno određenu javnu ulogu u jasno propisanom kostimu" (Bartlett prema Senett 2002: 021) do modernističkog subjekta koji „,masku” prefunkcionalizira, odnosno njegova odjeća postaje signal njegove individualiziranosti, „statusa, spola i osjećaja” (Bartlett prema Senett 2002: 021). Glazba i ples mediji su posredovanja te promjene, točnije, u tekstu je to glazbom vizualizirano tijelo koje emocionalno-plesnom kinetikom probija tipsku propisanost (Kolombine kao jednoga od likova commedie dell'arte, Batušić, Švacov 1986: 453) te subjekt oslobađa vezanosti uz zadani identitet:

Cello, flauta, oboa i bas,

A na balu, ko na valu Luna,

S obrazinom tajne od baršuna,

Kolombina mijenja lažni glas.

U Dijane nije ljepši stas

S ritmovima kao vruća struna,

Što se trza strasnih sa laguna

(...)

Otkud je, iz Rima, iz Pariza?

Što je, duvna, sablast il markiza,

Ili Venus, spremna leći svagda?

S maskom simbol, Žena i Sirena,

Sjeća me na Poea (...i Montepina!)

S okom mačke, zmije i smaragda

(Čuvida, Matoš 1996: 9). 
Uvođenje vremenski udaljenih, mitoloških likova (Luna, Dijana) te njihovo miješanje sa zbiljskima, odnosno mogućima, dodatno oslobađa subjekt identitetne vezanosti uz prostor, vrijeme, uz neku konkretnu zbilju, a s druge je strane i implicitna autoreferencijalna smjernica poetoloških koordinata teksta u smislu upućivanja na njegovu intertekstualnu dimenziju.

Krajnja svrha takvoga kulturalnog konstruiranja subjekta u kojemu je naglašeno lažiranje izgleda, odnosno identiteta, jest naglašavanje njegove hibridne (karnevalske) prirode, odnosno, prema Bahtinu (1978), naglašavanje njegove oslobođenosti od normativnih stega i strukturnih predodređenosti, tj. njegove otvorenosti svim identitetno-konstrukcijsko-semantičkim mogućnostima.

Karnevalizacijsko-plesna identifikacija drugoosobnog subjekta prisutna je i u pjesmi Djevojčici umjesto igračke, no tamo je simbolika vezana uz proces sociobiološkog sazrijevanja i dihotomnoga rodnog označavanja. Kada se u tekstu kaže: „Ljerko, srce moje, ti si lutka mala, / (...) Još je deset karnevala do tvog bala" (Matoš 1996: 29), konkretan socijalni običaj Matoševa vremena - ples pod maskama u svrhu upoznavanja mladih parova - postaje metafora sociobiološke geneze subjekta. Svi su relacionirani subjekti u tekstu prerušeni:

\author{
Al’ će doći veče kad ćeš, ko Elvira, \\ Don Huana sita i lažnih kavalira, \\ Sjetiti se sjetno nježne ove strofe. \\ Moje će ti ime šapnut moja muza, \\ A u modrom oku jecati će suza \\ Ko za mrtvim clownom iza katastrofe \\ (Djevojčici umjesto igračke, Matoš 1996: 29).
}

Njihove maske predstavljaju stereotipne rodne koncepte - lutka ženskost, socijalnu i seksualnu nevinost i podložnost, maske Don Huana i lažnih kavalira intertekstualne stereotipe muške moći i tjelesne žudnje, a maska clowna, kojom je usporedbom neizravno suoznačen prvoosobni subjekt-govornik, svojom je komično-tragičnom identitetnom semantikom nemoćan i neuspješan etički stabilizator takvih negativnih rodno-spolnih stereotipa. Može se, zapravo, reći kako su maske svih subjekata u ovom tekstu metaforičke sinegdohe arhetipskih rodno-spolnih odnosa (cf. Govedić 2001). 
Za razliku od takve neizravne autoidentifikacije, prvoosobni se i drugoosobni subjekti izravnije određuju u pjesmi Tajanstvena ruža, i to arhitekturnim i skulpturalnim motivima bašte, zida, gajeva, sfinge i zmajeva:

\author{
Jer duša moja bašta je daleka, \\ Visok zid je čuva, sfinga i zmajevi, \\ Tud šeta draga žena, duše jeka, \\ A njenim bićem struje sveti gajevi \\ (Tajanstvena ruža, Matoš 1996: 26).
}

Subjekt se u citiranim stihovima objavljuje kao spoznajno nedokučiva supstancija, kao biće čiji je integralni supstancijalni dio Ti instanca, a ta se nespoznatljivost, kao i odnos s Drugim, posreduju simboliziranom arhitekturizacijom prostora. Može se reći kako se ovdje događa radikalizacija teze njemačkog filozofa i teoretičara postmoderne Wolfganga Welscha da prostori oblikuju ljude (Welsch 2000). Prostori koji oblikuju subjekt ovdje su interiorizirani i u svojoj raščlanjenoj razlikovnosti predstavljaju različite stupnjeve subjektova bića. Kultivirani prostor prirode - bašta, potom vertikalna arhitekturna konstrukcija predimenzioniranog zida koji naliježe na prirodu te ima funkciju arhitekturnog štita bašte $i$, na koncu, nekultivirani prostor svetoga gaja kao simbolički korelativ najdubljeg dijela subjektova bića kojim je označena Ti instanca. Skulpturalni motivi sfinge i zmaja hijerarhijski su nadređeni arhitekturnima te predstavljaju svojevrsnu ambivalentnost simboličkih implikacija - ,sudbinsku neumitnost i destruktivnost" (Chevalier, Gheerbrant 2007). Može se reći kako arhitekturno načelo uspostavljanja Ja instance, kako ga naziva Josip Užarević (1991: 110-111), ovdje ima estetizacijske i ontološke implikacije.

U tekstu Serenada Matoš imenovanim arhitekturnim motivom, koji je identitetni amblem konkretnog, zagrebačkog prostora, usporedbom označava i subjektovu nacionalnu pripadnost kao njegovu primarnu identitetnu odrednicu:

Ja te volim jer si ljubav Zemlje Iz koje niknuh, Hrvatice draga:

Ko Bogomoljka na Kamenih vratih

Što dušom sija kada preko praga

Gričkog bruji mračni Angelus

(Serenada, Matoš 1996: 90-92). 
U pjesmi Jednoj i jedinoj, drugoosobni se subjekt metaforički poistovjećuje s glazbom („O, ti si sreća, ti si muzika, / Dušom mi tvojom zvoni duša sva" [Matoš 1996: 35-36]), čime se estetski doživljaj postavlja vrhovnim kriterijem prosudbe svijeta i Drugoga, dok se u tekstu Mističan sonet subjekt autoidentificira harfom kao sredstvom inferiorizacije u odnosu na Drugoga („O, kako čudno njene oči sijevahu / Kroz tajnu noći u slatkoj uspomeni! / A dušom mojom, njenom harfom, pjevahu, / Ja ne znam kakvi zvuci, psalam meni" [Matoš 1996: 37]).

Najčešće je ipak slikarsko posredovanje subjekta, pri čemu se misli na one pjesme u kojima je statičan prizor predstavljen slikarskim tehnikama i žanrovima (deskripcija bojama, dimenzijama, prostornim odnosima, portretiranje i sl.) te slikarskim proporcioniranjem predmeta i okvira uglavljen u grafiku pjesme (Prababa, Utjeha kose, Poznata neznanka, Dõ̃a muerte i dr.). Takve slikarske interpretacije različitim estetizacijskim postupcima i učincima idu u dva osnovna smjera koja onda svaki za sebe različito variraju - idu ,estetizaciji predmeta koji inače izazivlje nelagodu” i negativnoj estetizaciji ljepote (Kravar, Oraić Tolić 1996: 22).

\section{Zaključno, sintezno}

Matošev subjekt, kao karnevalsko-kazališni, glumački identitet, kao plesna i glazbena instanca, kao slikarski autor ili predmet, kao modna kreacija, identitetno je mozaično biće, vremenski i kulturalno kompleksno uvjetovano. Kako su analize pokazale, Matoš artističku koncepciju književnosti, iščitljivu u okviru „secesionističkoga pjesništva” (Slamnig 1981: 85 i slj.), provodi i drugomedijskim maskiranjem ili estetiziranjem lirskog subjekta, čime svoj tekst redovito rasteže i izvan granica njegove grafike, njegova književnog medija te daje implicitne informacije i o medijskokulturalnom kontekstu, odnosno o poetološkoj komunikaciji s tim kontekstom u smjeru simboličko-secesionističkih (korištenje intermedijalnih postupaka u uvođenju arhetipskih simbola poput ljubavi, smrti, duše, zida itd., u artificijeliziranu, mitološkim elementima prožetu/konstruiranu scenu pjesničkog teksta), impresionističkih (pristupanje prizoru kao sklopu pokretnih, estetiziranih, minimalističkih slika s naglašenom ekspresivnom funkcijom) i ekspresionističkih (očuđavanje zbilje interaktiranjem fikcijskih, mitoloških i mogućih likova i prostora) intervencija. 


\section{Literatura}

Bahtin M., 1978, Stvaralaštvo Fransoa Rablea, prev. I. Šop, T. Vučković, Beograd.

Bartlett Dj., 2002, Uzajamnosti društva i mode, u: Moda. Povijest, sociologija i teorija mode, ur. M. Cvitan-Černelić, Dj. Bartlett, A.T. Vladislavić, prev. A. Buljan et al., Zagreb, str. 17-31.

Batušić N., Švacov V., 1986, Drama, dramaturgija, kazalište, u: Uvod u književnost, ur. Z. Škreb, A. Stamać, Zagreb, str. 441-487.

Chevalier J., Gheerbrant A., 2007, Rječnik simbola: mitovi, sni, običaji, geste, oblici, likovi, boje, brojevi, prev. D. Bučan, A. Buljan, N. Grujić, F. Vučak, M. Vekarić, Zagreb.

Govedić N., 2001, Prepoznavanje i prerušavanje izvedbenog tijela, ,Treća” br. 1-2, str. $102-115$.

Jukić S., 2011, Stilistika medijskoga subjekta u suvremenom hrvatskome pjesništvu, doktorski rad, Zagreb.

Katarinčić I., 2005, Zagrebačke plesne zabave s kraja 18. i tijekom 19. stoljeća, „Narodna umjetnost" br. 2, str. 49-68.

Klaić V., 1979, Rječnik stranih riječi, Zagreb.

Kravar Z., Oraić Tolić D., 1996, Lirika i proza Antuna Gustava Matoša, Zagreb.

Matoš A.G., 1973, Sabrana djela, sv. 11, O likovnim umjetnostima. Putopisi, ur. S. Batušić, D. Jelčić, Zagreb.

Matoš A.G., 1996, Izabrane pjesme, Zagreb.

Oraić Tolić D., 2003, Vizualnost u hrvatskoj prozi 20. stoljeća. Matoš, Krleža, Pavličić, u: Vizualnost, ur. A. Flaker, J. Užarević, Zagreb, str. 381-396.

Rem G., 2011, Pogo i tekst, Zagreb.

Slamnig I., 1981, Hrvatska versifikacija: narav, povijest, veze, Zagreb.

Šuvaković M., 2005, Pojmovnik suvremene umjetnosti, Zagreb.

Užarević J., 1991, Kompozicija lirske pjesme, Zagreb.

Welsch W., 2000, Prostori oblikuju ljude, prev. D. Barbarić, „Europski glasnik” br. 5, str. 617-640. 
